\title{
DIFICULDADES DE INGRESSANTES DE UM CURSO DE LICENCIATURA EM QUÍMICA SOBRE CONCEITOS DA ELETROQUÍMICA: UM DESAFIO PARA O ENSINO SUPERIOR
}

\author{
Gabriela Venturia , Ermelinda Silvana Junckes ${ }^{a}$, Maria da Graça Moraes Braga Martin ${ }^{\mathrm{a}}$ e Brenno Ralf Maciel Oliveira ${ }^{\mathrm{a}, *,(])}$ \\ a'Departamento de Química, Centro de Ciências Tecnológicas, Universidade do Estado de Santa Catarina, 89219-710 Joinville - \\ SC, Brasil
}

Recebido em 21/07/2020; aceito em 14/12/2020; publicado na web em 22/04/2021

\begin{abstract}
DIFFICULTIES OF CHEMISTRY NEW UNDERGRADUATE STUDENTS AS REGARDS ELECTROCHEMICAL CONCEPTS: A CHALLENGE FOR HIGHER EDUCATION. The present work discusses some of the difficulties that chemistry undergraduates have with electrochemistry and possible impacts on higher education. They responded to a questionnaire about their insights and experiences regarding electrochemistry teaching, as well as their knowledge about it. The responses were categorized according to their difficulties, mistakes, and alternative views, by means of content analysis. The data revealed that undergraduates often enter the course without solid previous knowledge about redox phenomena, since few of them managed to develop more elaborate and correct responses, directly impacting the continuity of electrochemical studies in higher education.
\end{abstract}

Keywords: chemistry teaching; redox; misconceptions.

\section{INTRODUÇÃO}

A química é uma ciência básica fundamental na formação do cidadão, mas exige criatividade e abstração por parte dos estudantes e professores, especialmente na educação básica. Muitas vezes, a partir desse caráter abstrato, concepções alternativas são construídas e/ou reforçadas durante o processo de ensino-aprendizagem, seja por meio de erros conceituais e contextuais, por uso de analogias, ou falha na interpretação. ${ }^{1}$

Conhecer melhor essas dificuldades dos estudantes torna-se ferramenta essencial à prática do professor, uma vez que o auxilia a compreender melhor os processos pelos quais seus alunos constroem conhecimentos e seus mecanismos de pensamento, e contribui no direcionamento da ação pedagógica do professor e no planejamento de suas intervenções didáticas. ${ }^{2}$ Trata-se de uma medida de precaução, que todo professor deveria ter conhecimento antes de iniciar seu planejamento, mas também de uma ação constante, retroalimentada, em que durante o desenvolvimento das aulas o professor vai tomando conhecimento e reorganizando sua ação a partir disso. ${ }^{3}$

Nesse sentido, conhecer as dificuldades, equívocos e concepções alternativas que os estudantes possuem nos mais diversos conteúdos de química, bem como compreender suas possíveis causas, torna-se uma ação de grande relevância na prática docente.

Já no ensino médio, os alunos têm dificuldade em resolver problemas contextuais de eletroquímica, mesmo que consigam resolver questões de algoritmos e cálculos. ${ }^{4} \mathrm{~A}$ compreensão de conceitos eletroquímicos necessita de raciocínio elaborado e complexo, bem como a relação com fenômenos macroscópicos, ${ }^{5} \mathrm{e}$ nem sempre os estudantes conseguem atingir essa compreensão em sua completude.

Alguns trabalhos buscaram evidenciar na literatura quais são as principais dificuldades enfrentadas pelos alunos em eletroquímica, revelando problemas com o ensino e aprendizagem acerca de conceitos como o de corrente elétrica, dos processos de oxirredução, das pilhas, do potencial padrão, entre outros. ${ }^{5-15}$ Nessa perspectiva, também ganham notoriedade na discussão as concepções alternativas que envolvem os conceitos de ponte salina, ânodo e cátodo, de

\footnotetext{
*e-mail: brenno.oliveira@udesc.br
}

diferença de potencial e do próprio funcionamento das pilhas eletroquímicas. . $^{7,10,12,13}$

Algumas pesquisadoras notaram que os alunos do ensino médio conhecem muito pouco a respeito de fenômenos microscópicos envolvidos na produção e no fluxo de corrente elétrica. ${ }^{1}$ Essas autoras concluíram que os estudantes têm a tendência a compartimentar os conteúdos das aulas de Química e Física, não estabelecendo uma relação entre os fenômenos comuns das disciplinas, especialmente quanto à eletricidade envolvida no funcionamento das pilhas. Diante disso, identificaram que os estudantes possuíam concepções alternativas como, por exemplo, ao tentarem explicar o fluxo de carga em solução.

O discurso e a linguagem utilizada pelos professores são outros aspectos que devem ser considerados no processo de ensinoaprendizagem. Ou seja, a linguagem utilizada pelos professores também pode influenciar na construção e/ou reforço dessas concepções, como nos casos em que o professor se refere aos eletrodos pelos nomes dos metais e suas cargas.

Além disso, a abordagem destes conteúdos feita pelos livros didáticos pode também representar uma possibilidade de conduzir os estudantes a construírem e/ou reforçarem suas concepções alternativas. ${ }^{14} \mathrm{Um}$ estudo brasileiro verificou que a abordagem feita sobre a eletroquímica nos livros didáticos e as suas ilustrações poderiam levar à construção de algumas concepções alternativas, como no caso da atribuição de uma posição específica para cátodo e ânodo nas representações de pilhas. ${ }^{8}$

Quando as dificuldades, equívocos e concepções alternativas dos estudantes não são problematizadas ou desconstruídas, podem acompanhá-los durante toda sua trajetória escolar na educação básica e, inclusive, no ensino superior. Nesse sentido, essa "herança" leva o estudante a apresentar ainda mais dificuldades em assimilar novos conceitos durante a graduação ou até mesmo em utilizar os conceitos básicos de maneira correta e integrada. ${ }^{6,7,12}$ Essa problemática ainda se agrava, no caso da licenciatura, quando essa mesma "herança" acompanha o estudante ao término de sua graduação e o mesmo vai atuar como professor, fazendo com que o conteúdo, quando trabalhado, seja explorado de forma simplista ou até mesmo equivocada. ${ }^{2}$

Diante desse cenário, reafirmamos a importância de discutir sobre as dificuldades, os equívocos e as concepções alternativas dos 
estudantes nos mais diversos conceitos estudados na química, como forma de construir novos caminhos para a instrumentalização do professor em sua ação docente. Nesse sentido, o objetivo do presente trabalho é o de identificar as dificuldades, equívocos e concepções alternativas de alunos ingressantes em um curso de Licenciatura em Química sobre os conceitos relacionados à eletroquímica.

\section{PERCURSO METODOLÓGICO}

Inicialmente, elaborou-se um questionário, inspirado em uma pesquisa de autores brasileiros, ${ }^{1}$ que foi validado a partir de uma aplicação piloto realizada com 3 estudantes e posterior discussão com dois professores do ensino superior acerca das readequações necessárias. Após esse processo, o questionário foi aplicado com 25 graduandos de uma turma da primeira fase de um curso de Licenciatura em Química de uma universidade pública de Santa Catarina. A escolha de uma turma da primeira fase se deu pelo fato de que os alunos ainda não teriam estudado o conteúdo de eletroquímica na graduação, de modo que suas respostas trariam basicamente os conhecimentos advindos das vivências anteriores como, por exemplo, as aulas de química no ensino médio e/ou cursos pré-vestibular.

O questionário foi elaborado com três partes, sendo que cada uma atenderia a um objetivo específico. Na primeira parte, buscouse caracterizar o público alvo e conhecer informações básicas como a idade e o tempo que o acadêmico já havia concluído o ensino médio. Além disso, o questionário possibilitou quantificar os alunos provenientes da rede pública e os alunos da rede privada de ensino, e se o indivíduo participou ou não de curso pré-vestibular. Nessa etapa do questionário, o acadêmico pôde informar se teve aulas sobre eletroquímica durante o ensino médio e quais recursos didáticos o seu professor utilizava em suas aulas com o intuito de agregar o processo de ensino e aprendizagem.

A segunda parte do questionário é o objeto central da discussão deste trabalho, cujos dados são analisados. O objetivo dessa parte foi de identificar as principais dificuldades, equívocos e concepções alternativas dos estudantes no processo de aprendizagem do conteúdo de oxirredução. O Quadro 1 apresenta as quatro questões que compuseram essa parte do questionário.

Optou-se por não fornecer os valores de potencial padrão das reações, a fim de priorizar a reflexão qualitativa dos fenômenos por parte dos estudantes, de modo que pudessem explorar puramente suas próprias concepções acerca dos conceitos envolvidos ao invés de seguirem possíveis raciocínios mecânicos envolvendo aspectos matemáticos a partir dos valores de potencial fornecidos.

Na terceira parte do questionário, buscou-se conhecer a perspectiva dos acadêmicos de licenciatura sobre o processo de ensino e aprendizagem do conteúdo de eletroquímica durante sua trajetória escolar. Sendo assim, solicitou-se que os graduandos avaliassem de 0 à 10 o nível de dificuldade em aprender e em ensinar eletroquímica, e ressaltassem quais os conteúdos químicos os mesmos consideravam indispensáveis como conhecimento prévio ao compreender oxirredução, além das dificuldades em ensinar e aprender eletroquímica.

Os dados coletados foram organizados e analisados utilizandose dos procedimentos da análise de conteúdo, ${ }^{16}$ com categorias estabelecidas à priori, que foram construídas a partir de uma adaptação de um levantamento ${ }^{17}$ sobre dificuldade, equívoco e concepção alternativa (DECA) dos estudantes em eletroquímica, reportadas na literatura, conforme o Quadro 2.

Além das DECAs apresentadas no Quadro 2, criaram-se outras categorias necessárias na análise dos dados, que foram identificadas numericamente na sequência a contagem das DECAs: Classe 42. Afirmou não lembrar, não saber ou não respondeu; Classe 43 .
Quadro 1. Segunda parte do questionário aplicado com os licenciandos em Química

1) O que você entende por número de oxidação?

2) Como você determina qual eletrodo é o cátodo e qual é o ânodo em uma célula galvânica e em uma célula eletrolítica?

3) Na pilha representada abaixo, a oxidação do níquel introduz íons níquel adicionais na semicélula $\mathrm{A}$ e a redução dos íons prata deixa um excesso de cargas negativas na semicélula B:

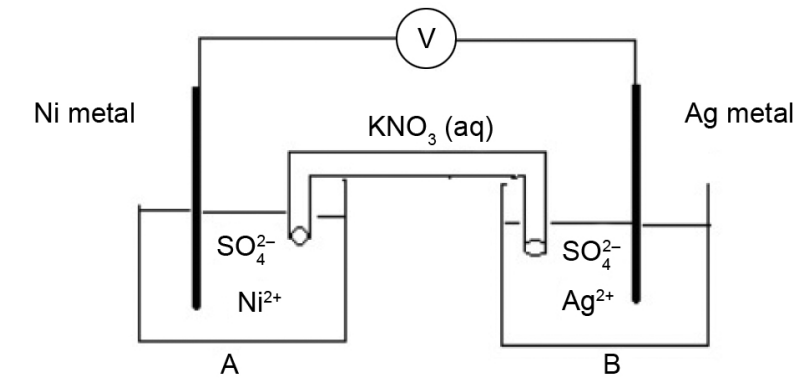

a) Explique como a corrente elétrica é produzida nesta pilha.

b) Explique, através de palavras ou desenhos, o movimento das cargas (íons e/ou elétrons), de forma a produzir corrente elétrica.

c) Escreva as semi-reações de oxidação e de redução que ocorrem na pilha acima.

d) Determine qual eletrodo é o cátodo e qual é o ânodo, bem como os polos negativos e positivos.

e) Como você determina qual espécie sofreu oxidação e qual sofreu redução?

f) Qual é a finalidade da ponte salina?

4) A obtenção de vários materiais utilizados pelo homem é realizada através do processo da eletrólise. O equipamento abaixo foi utilizado para efetuarmos a eletrólise de uma solução aquosa de cloreto de cobre II $\left(\mathrm{CuCl}_{2}\right)$ com eletrodos de carbono:

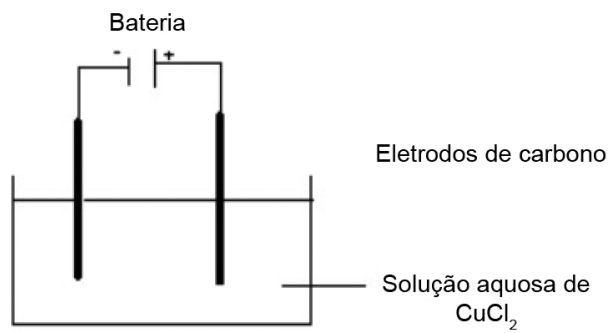

a) Escreva/indique o sentido do movimento das cargas (íons positivos, íons negativos e elétrons) nesta célula através dos fios e na solução durante o processo da eletrólise.

b) Explique a origem da(s) corrente(s) existente(s) neste equipamento.

c) Determine qual eletrodo é o cátodo e qual é o ânodo, bem como os polos negativos e positivos.

d) O que acontece na solução durante o processo da eletrólise? Justifique.

Fonte: os autores (2020).

Resposta incorreta ou parcialmente correta, sem apresentar DECAs; Classe 44. Respondeu algo diferente do que foi solicitado, fugindo do assunto; Classe 45. Resposta correta.

\section{RESULTADOS E DISCUSSÃO}

Em relação à idade dos participantes desse estudo, observou-se que grande parte dos alunos possuía idade entre 17 e 19 anos, e apenas três alunos possuíam entre 21 e 25 anos. Dentre os 25 acadêmicos, 9 disseram ter estudado toda a educação básica em escola pública, 7 alunos estudaram toda a educação básica em escola privada e 9 disseram ter estudado parcialmente em escola pública e privada. Apenas 7 alunos 
Quadro 2. Dificuldade, equívoco ou concepção alternativa

\begin{tabular}{|c|c|}
\hline ASSUNTO & DECA \\
\hline Oxidação e Redução & $\begin{array}{l}\text { 1. Estado de oxidação de um elemento é o mesmo que a carga do íon monoatômico desse elemento. } \\
\text { 2. Em todas as equações, a adição e a remoção de oxigênio podem ser usadas para identificar uma reação de oxidação ou redução. } \\
\text { 3. Nas equações químicas, a mudança de cargas de espécies poliatômicas pode ser usada para identificar uma reação de oxidação } \\
\text { ou redução. } \\
\text { 4. Os processos de oxidação e redução ocorrem independentemente. } \\
\text { 5. Números ou estados de oxidação podem ser atribuídos a moléculas poliatômicas ou a íons. } \\
\text { 6. A carga das espécies poliatômicas indica o estado de oxidação da molécula ou íon. } \\
\text { 7. Em uma equação, mudanças nas cargas de espécies poliatômicas podem ser usadas para determinar o número de elétrons } \\
\text { removidos ou ganhos pelas espécies reativas. }\end{array}$ \\
\hline Corrente Elétrica & $\begin{array}{l}\text { 8. A eletricidade na química e na física é diferente porque o fluxo da corrente ocorre em direçães opostas. } \\
\text { 9. Elétrons movem-se em solução pela atração alternada de um íon para o outro. } \\
\text { 10. Quando um eletrólito conduz corrente, os elétrons movem-se para um íon no cátodo e são transportados por esse íon para o } \\
\text { ânodo. } \\
\text { 11. Em uma pilha os ânions e cátions são atraídos uns pelos outros e isso afeta o movimento dos íons nos eletrodos. } \\
\text { 12. Elétrons movem-se através dos eletrólitos por serem atraídos por íons positivos em solução. } \\
\text { 13. Prótons fluem nos condutores metálicos. } \\
\text { 14. A corrente convencional é o fluxo de cargas positivas (geralmente prótons). } \\
\text { 15. Os elétrons fluem nos eletrólitos. } \\
\text { 16. Prótons e elétrons fluem em direções opostas em um eletrólito. } \\
\text { 17. O movimento de íons em solução não constitui uma corrente elétrica. } \\
\text { 18. Elétrons podem fluir pela solução aquosa sem assistência dos íons. } \\
\text { 19. Apenas as cargas negativas constituem o fluxo de corrente no eletrólito e na ponte salina. } \\
\text { 20. Prótons fluem em eletrólitos (independentemente se a solução é ácida, básica ou neutra). }\end{array}$ \\
\hline Ponte Salina & $\begin{array}{l}\text { 21. Em uma célula eletroquímica, a ponte salina fornece elétrons necessários para completar o circuito. } \\
\text { 22. A ponte salina auxilia no fluxo de corrente (ou seja, no fluxo de elétrons porque os íons positivos na ponte atraem os elétrons } \\
\text { de uma meia-célula para outra meia-célula). } \\
\text { 23. Ânions na ponte salina e nos eletrólitos aceitam elétrons e transferem do cátodo para o ânodo. } \\
\text { 24. Cátions na ponte salina e no eletrólito aceitam elétrons e transferem do cátodo para o ânodo. }\end{array}$ \\
\hline Ânodo e Cátodo & $\begin{array}{l}\text { 25. O ânodo é carregado positivamente porque ele perde elétrons e o cátodo é carregado negativamente porque ganha elétrons. } \\
\text { 26. O ânodo é carregado negativamente e por isso atrai cátions, o cátodo é carregado positivamente e por isso atrai ânions. } \\
\text { 27. Nas tabelas de potenciais de redução padrão. A espécie com maior potência é o ânodo. } \\
\text { 28. A lista de potencial padrão de redução coloca a reatividade dos metais em ordem decrescente de cima para baixo. } \\
\text { 29. A identificação do ânodo e do cátodo depende da localização física da meia-célula. } \\
\text { 30. Ânodos, como ânions, sempre são carregados negativamente, cátodos, como cátions, são carregados positivamente. }\end{array}$ \\
\hline Diferença de Potencial & $\begin{array}{l}\text { 31. Uma diferença de potencial entre dois pontos é exclusivamente devido a diferente na concentração de carga nesses pontos. } \\
\text { 32. Há uma concentração elevada de elétrons no ânodo. } \\
\text { 33. Existe uma baixa concentração de elétrons no cátodo. } \\
\text { 34. Os elétrons deixam o ânodo, onde existe uma elevada concentração de elétrons e movem-se através do circuito externo para } \\
\text { o cátodo, onde existe uma baixa concentração de elétrons. } \\
\text { 35. A designação do } \mathrm{E}^{\circ} \text { para uma semicélula padrão } \mathrm{H}_{2}(1 \mathrm{~atm}) / \mathrm{H}^{+}(1 \mathrm{M}) \text { ser zero não é arbitrária, pois é baseada na química do } \\
\mathrm{H}^{+} \text {e } \mathrm{H}_{2} \text {. } \\
\text { 36. Não há necessidade de uma meia-célula padrão. } \\
\text { 37. Potenciais de meia célula são absolutos na natureza e podem ser usados para predizer a espontaneidade das meias células. } \\
\text { 38. Potenciais das células são derivados da adição individual dos potenciais de redução. } \\
\text { 39. Potenciais de meia célula não são propriedades intensivas. }\end{array}$ \\
\hline $\begin{array}{l}\text { Funcionamento das } \\
\text { Pilhas Eletroquímicas }\end{array}$ & $\begin{array}{l}\text { 40. Elétrons entram na solução pelo cátodo, viajem pelo eletrólito (e/ou pela ponte salina) e emergem no ânodo para completar } \\
\text { o circuito. } \\
\text { 41. Nas células eletroquímicas, os ânions e cátions movem-se até que suas concentrações nas meias células sejam iguais. }\end{array}$ \\
\hline
\end{tabular}

Fonte: Adaptado de Goes et al. ${ }^{17}$

cursaram pré-vestibulares. A maioria dos alunos (21) concluiu o ensino médio entre 6 meses e dois anos antes da realização do presente estudos.

Quando questionados se aprenderam os conceitos de eletroquímica durante a educação básica e sobre os recursos didáticos explorados pelo professor, 16 alunos relataram que aprenderam o assunto na $2^{\mathrm{a}}$ série do ensino médio. Grande parte dos alunos disse que suas aulas eram baseadas apenas em conceitos teóricos e avaliações pontuais (do tipo prova escrita), com abordagem superficial e descontextualizada. Apenas 2 alunos afirmaram ter tido aulas práticas de química desse conteúdo e 16 disseram que o principal recurso explorado pelo professor era o livro didático (alguns desses estudantes apontaram também o uso do quadro). Além disso, alguns estudantes (4) comentaram que seus professores não eram bem preparados e não explicavam de forma clara e outros (2) disseram que suas aulas de química eram planejadas com foco apenas no Exame Nacional do Ensino Médio e vestibulares, com macetes, fórmulas e conceitos decorados, por meio de uma aprendizagem mecânica.

De modo geral, verifica-se que os sujeitos do presente estudo concluíram o ensino médio pouco tempo antes de ingressarem no ensino superior e que, quando tiveram o conteúdo de eletroquímica durante a educação básica, a abordagem realizada pelos professores foi bastante simplória, sem o uso de recursos didáticos diferenciados e, às vezes, com pouco domínio conceitual por parte do docente.

Atualmente, muito se discute na literatura sobre a importância de uma abordagem contextualizada, a qual conecta os conceitos químicos vistos em sala de aula com as suas aplicações presentes no cotidiano do estudante. Pela perspectiva dos Parâmetros Curriculares Nacionais para o Ensino Médio (PCNEM) ${ }^{18}$ contextualizar o ensino de química significa assumir que todo o conhecimento envolve uma relação entre o sujeito e o objeto - logo, a contextualização no ensino de química é um recurso que traz consigo um novo significado aos 
conceitos ensinados no ambiente escolar, possibilitando ao estudante uma aprendizagem significativa da química.

Ainda de acordo com o PCNEM, ${ }^{18}$ a experimentação faz parte da vida, na escola ou no cotidiano de todos nós. Assim, a ideia de experimentação como atividade exclusiva das aulas de laboratório, onde os alunos recebem uma receita a ser seguida nos mínimos detalhes e cujos resultados já são previamente conhecidos, não condiz com o ensino atual. As atividades experimentais devem partir de um problema, de uma questão a ser respondida. Cabe ao professor orientar os alunos na busca de respostas. As questões propostas devem propiciar oportunidade para que os alunos elaborem hipóteses, testemnas, organizem os resultados obtidos, reflitam sobre o significado de resultados esperados e, sobretudo, o dos inesperados, e usem as conclusões para a construção do conceito pretendido. As habilidades necessárias para que se desenvolva o espírito investigativo nos alunos não estão associadas a laboratórios modernos, com equipamentos sofisticados. Muitas vezes, experimentos simples, que podem ser realizados em casa, no pátio da escola ou na sala de aula, com materiais do dia-a-dia, levam a descobertas importantes.

Em relação à segunda parte do questionário, na questão 1, solicitou-se aos estudantes que explicassem seu entendimento sobre o conceito de número de oxidação (NOX). Na literatura esse conceito é trazido como carga aparente de um átomo em um íon ou molécula, que representa a tendência desse átomo em atrair os elétrons das ligações que ele realiza. ${ }^{19}$ Os resultados revelaram que 3 alunos deram respostas em que foram identificadas DECAs, 6 alunos não responderam, 12 responderam de forma incorreta sem a identificação de DECAs, 3 escreveram respostas sem relação com o questionamento, e apenas 1 aluno respondeu de forma correta. A Figura 1 apresenta as categorias identificadas nas respostas dos alunos para a primeira questão.

O que você entende por número de oxidação?

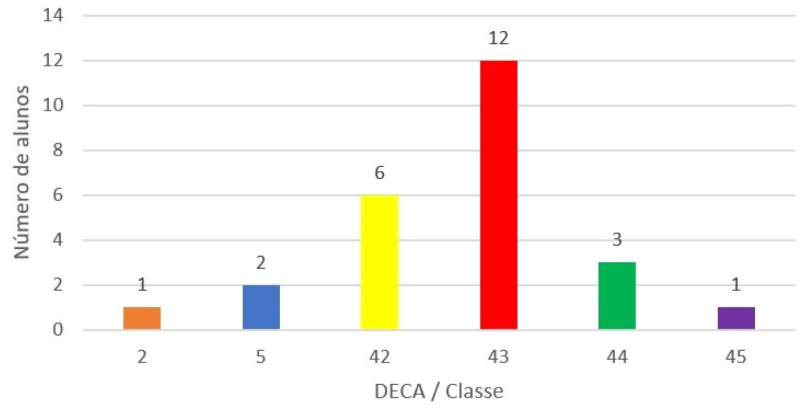

Figura 1. Categorias identificadas nas respostas à primeira questão

A Figura 1 mostra que a resposta de 1 aluno foi categorizada na DECA 2 ("Em todas as equações, a adição e a remoção de oxigênio podem ser usadas para identificar uma reação de oxidação ou redução") e a de 2 alunos na DECA 5 ("Números ou estados de oxidação podem ser atribuídos a moléculas poliatômicas ou a íons").

Algumas das respostas incorretas fornecidas foram: "Coeficiente do elemento necessário para neutralizarmos a reação"; " $N{ }^{o}$ de perdas de elétrons de um metal"; "Número que se pode encontrar na tabela periódica segundo sua localização”. Outras respostas como, por exemplo, "Quantos elétrons vai ganhar ou perder", "Número de elétrons que o elemento elou composto doa ou recebe para que a carga seja neutra" foram consideradas como incorretas por apresentarem explicações incompletas ou pequenos erros que não caracterizam completamente a identificação de alguma DECA.

Observou-se que os alunos apresentaram relativa dificuldade em explicar o conceito de NOX, respondendo o que é oxidação e redução ao invés de responder, de fato, o questionamento. Parece que alguns alunos assumem esses conceitos como a própria definição de NOX uma vez que estão diretamente relacionados. Alguns estudantes entendem o NOX como a carga efetiva dos átomos. As respostas dos estudantes indicam também que parece haver uma confusão sobre número de oxidação e número atômico, ou com a carga de íons, bem como sobre o conceito de NOX se aplicar apenas a átomos metálicos, muito usados em exemplos eletroquímicos. As respostas que fugiram do assunto abordado na questão também podem indicar dificuldade dos alunos em definir o conceito de NOX.

Quando questionados sobre como determinar qual eletrodo é o cátodo e qual eletrodo é o ânodo nas células galvânicas e eletrolíticas, na questão 2, 3 alunos forneceram respostas em que foram identificadas DECAs, 7 alunos não responderam, 14 alunos responderam de forma incorreta e 1 aluno respondeu corretamente. A Figura 2 representa os resultados da análise das respostas para a segunda questão.

Como você determina qual eletrodo é o cátodo e qual eletrodo é o ânodo em uma célula eletroquímica e em uma célula eletrolítica?

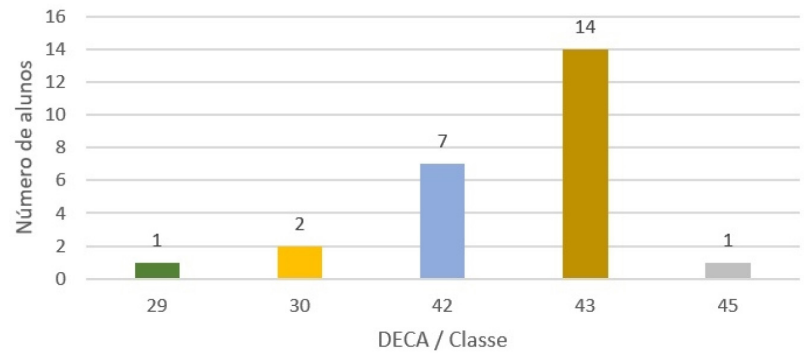

Figura 2. Categorias identificadas nas respostas à segunda questão

Dentre as respostas incorretas, vários estudantes afirmaram que o ânodo é sempre o polo negativo e o cátodo é sempre o polo positivo, independente da célula. Observa-se que os estudantes utilizam como base de suas explicações o fato de o polo ser positivo ou negativo para a identificação dos eletrodos, ao invés das reações de oxidação ou redução que ocorrem nos mesmos.

A análise das respostas que apresentaram DECAs permitiu verificar que 1 aluno identificou o cátodo e o ânodo pelas posições físicas dos eletrodos na representação da célula galvânicas, enquanto outros 2 estudantes os relacionaram com a carga de íon (possivelmente confundindo devido à similaridade das palavras ânodo e ânion, cátodo e cátion), como pode-se observar nas respostas: "Verifico os íons das células eletrolíticas. Cátodo, íon cátion. Ânodo, íon ânion"; "Primeiro que o cátion está sempre a frente do ânion, segundo o cátion reduz e o ânion oxida, terceiro por experiência lembrar as cargas"; "Cátodo $($ cátion $)=$ carga positiva. Ânodo $($ ânion $)=$ carga negativa".

Chama a atenção a quantidade de estudantes que não respondeu ou afirmou não saber como identificar o cátodo e o ânodo, totalizando 7 alunos. Algumas das respostas agrupadas na classe 43 são: "Só saberia que o cátodo é positivo e o ânodo é negativo. Não tenho ideia do que é eletrolítico"; "O cátodo sempre será o polo positivo e a barrinha do seu elemento irá aumentar a massa, já o ânodo sempre será sempre o polo negativo e irá diminuir sua massa"; "O ânodo é negativo, ocorre corrosão. Cátodo é positivo, ocorre oxidação”; "Cátodo ganhará elétrons, ânodo perderá elétrons. Eletrodo será inverso dependendo da situação”. Há a ideia de que os eletrodos possuem polaridade fixa (negativa ou positiva), denotado pelo uso da palavra "sempre", quando, na verdade, os polos são diferentes nas células eletroquímicas e nas células eletrolíticas.

A análise realizada sobre as respostas para a questão 3 e as categorias observadas estão representadas pela Figura 3. 
Na pilha representada abaixo, há oxidação do níquel na semicélula $\mathrm{A}$ e redução de íons de prata na semicélula $\mathrm{B}$.

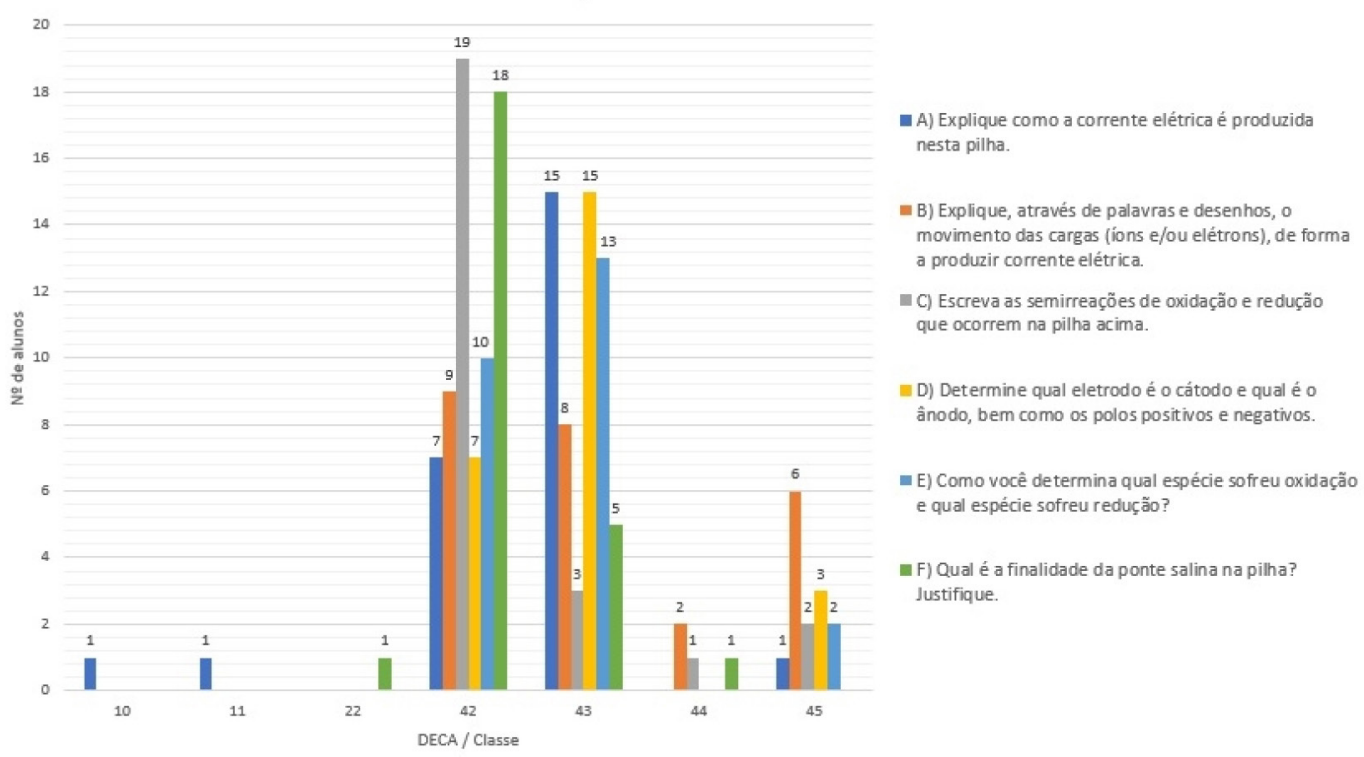

Figura 3. Categorias identificadas nas respostas à terceira questão

Na questão 3a, identificou-se a DECA 10 em 1 resposta ("Quando um eletrólito conduz corrente, os elétrons movem-se para um íon no cátodo e são transportados por esse íon para o ânodo") e a DECA 11 em outra resposta ("Em uma pilha os ânions e cátions são atraídos uns pelos outros e isso afeta o movimento dos íons nos eletrodos"). Além disso, 7 estudantes não responderam, 15 responderam de forma incorreta e apenas 1 soube explicar corretamente como a corrente elétrica é produzida na pilha a partir das reações de oxidação e redução.

A questão 3 b solicitava que o aluno explicasse e representasse $o$ movimento das cargas para que a corrente elétrica fosse produzida. Dentre os 25 alunos, 6 alunos representaram o movimento de cargas corretamente e outros 9 não responderam. 8 respostas foram consideradas incorretas e duas fugiram do assunto. Nas respostas dos estudantes não foram identificadas DECAs.

Algumas das respostas foram consideradas incorretas por apresentarem desenhos em que representaram por meio de flechas o movimento das cargas, que ocorria a partir dos elétrons saindo da espécie que reduz em direção ao metal que oxida, pelo fio condutor que liga os eletrodos representados na figura da pilha, como mostra a Figura 4.

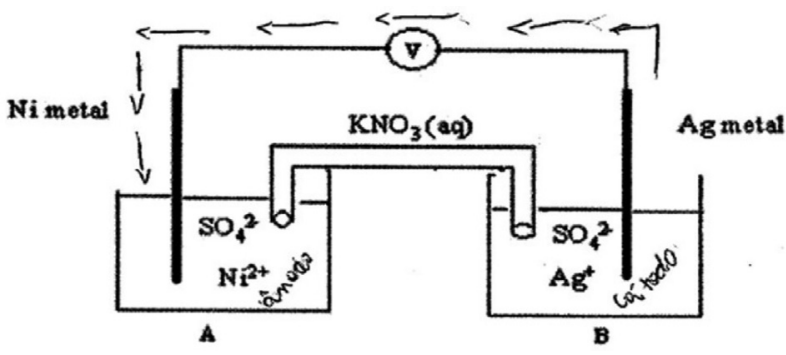

Figura 4. Resposta fornecida por um aluno à questão $3 b$

Algumas respostas, como na Figura 5, não deixaram explícito como acontecia o movimento de cargas na célula, nem sequer indicando-o por setas ou desenhos, sendo consideradas como incorretas também.

A questão $3 \mathrm{c}$ solicitava que os estudantes escrevessem as semireações de oxidação e redução que ocorriam na pilha. Apenas 6 alunos responderam, sendo que 2 responderam corretamente. Uma

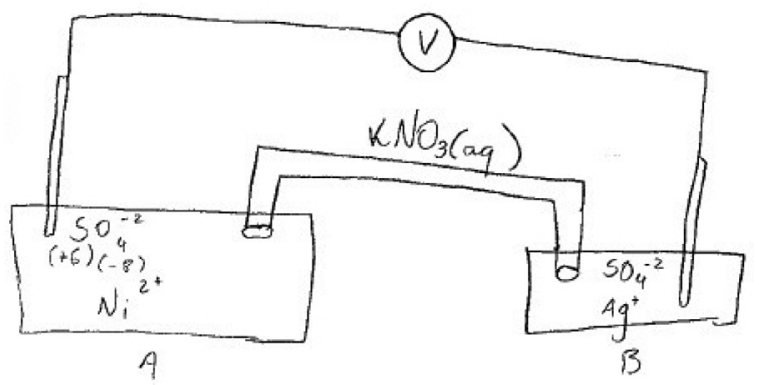

Figura 5. Resposta fornecida por um aluno à questão $3 b$

resposta fugiu completamente do assunto abordado e outras 3 foram consideradas incorretas, pois as semi-reações foram representadas erroneamente, ou ainda, representaram reações envolvendo o nitrato de potássio $\left(\mathrm{KNO}_{3}\right)$ utilizado na ponte salina, ao invés das espécies que, de fato, estão envolvidas nas reações.

O resultado obtido nessa questão pode revelar a dificuldade que os alunos possuem em compreender e identificar as reações de oxidação e redução que estão ocorrendo, bem como de dominar o nível representacional, ou seja, representar em forma de equação química o que acontece na reação.

$\mathrm{Na}$ questão $3 \mathrm{~d}$, em que era solicitado ao aluno que indicasse o cátodo e o ânodo na pilha, bem como os seus polos, a maioria da turma (15 alunos) respondeu de forma incorreta: o erro mais comum foi confundir ânodo e cátodo, alegando que no cátodo é onde ocorre a oxidação e no ânodo a redução. Na questão 3 d, 3 estudantes responderam corretamente, enquanto 7 não responderam. Mais uma vez, o resultado aponta para uma possível dificuldade em compreender os processos de oxidação e redução, bem como de identificá-los na reação.

A questão $3 \mathrm{e}$ pedia para que o acadêmico determinasse e explicasse qual espécie sofreu redução e qual espécie sofreu oxidação. Apenas 2 alunos souberam responder à questão corretamente, 13 alunos elaboraram respostas incorretas e 10 alunos não responderam à questão ou afirmaram não se lembrar ou não saber como responder. Um aluno apresentou a seguinte resposta: "Através da relação/método citado anteriormente na questão 7. (DONA PORCA)” e embora seja um macete de memorização muito utilizado, não permite que 
os autores compreendam a forma com que o estudante interpreta e utiliza tal macete.

Na questão 3f, o aluno deveria explicar qual a finalidade da ponte salina na pilha. As respostas revelaram um aspecto preocupante acerca da base de conhecimentos dos estudantes sobre os componentes e o funcionamento de uma pilha, pois dentre os 25 estudantes, 18 não responderam, 5 responderam de forma incorreta sem identificação de DECA (por exemplo: "A ponte salina serve para diminuir a oxidação de uma pilha") e 1 fugiu do assunto (por exemplo "O $\mathrm{NaCl} e ́$ um bom condutor de energia”). Embora algumas respostas consideradas incorretas traziam consigo um erro comum de atribuir a passagem de elétrons pela ponte salina, as respostas não apresentaram elementos suficientes para serem categorizadas em alguma DECA. Em uma resposta foi identificada a DECA 22 ("A ponte salina auxilia no fluxo de corrente - ou seja, no fluxo de elétrons porque os íons positivos na ponte atraem os elétrons de uma meia-célula para outra meia-célula").

A análise realizada sobre as respostas para a questão 4 e as categorias identificadas estão representadas pela Figura 6 .

A questão 4a pedia para que o aluno escrevesse/indicasse o sentido do movimento das cargas na célula durante o processo. Apenas 3 alunos responderam corretamente; 11 responderam incorretamente e 11 não responderam. Alguns estudantes não especificaram as espécies envolvidas e as regiões da célula em que ocorriam os movimentos das cargas, apresentando respostas apenas como "Da direita para a esquerda" e, por isso, foram consideradas como respostas incorretas.

$\mathrm{Na}$ questão $4 \mathrm{~b}$, o estudante deveria explicar a origem da(s) corrente(s) existente(s) no equipamento e 16 estudantes não a responderam, enquanto que 9 responderam incorretamente. Dentre as respostas consideradas incorretas, 4 estudantes deram respostas gerais como "A origem da corrente elétrica é pela diferença de potencial dos eletrodos" que não forneceram subsídio para uma análise mais aprofundada. Algumas respostas foram consideradas erradas por utilizarem a interpretação similar a um processo espontâneo

A questão $4 \mathrm{c}$ solicitava que o estudante indicasse o cátodo e o ânodo, bem como o polo negativo e o polo positivo. Apenas 1 aluno respondeu corretamente, 12 alunos não responderam e 12 responderam de forma incorreta. Novamente, o erro mais comum dos estudantes foi confundir os conceitos de cátodo e ânodo, de oxidação e redução, ou ainda, de basear a classificação de ânodo e cátodo, bem como os polos, pela posição física dos eletrodos. Além disso, alguns alunos classificaram o gás cloro formado como o ânodo.

A questão $4 d$ pedia para que o estudante explicasse o que acontecia na solução durante o processo da eletrólise. Mais da metade da turma não respondeu (14) e 11 responderam incorretamente.

De modo geral, na questão 4 (do item a ao d), não foi possível identificar DECAs nas respostas, especialmente pelo baixo índice de respostas. Em média, 13 alunos deixaram de responder à questão, sendo a $4 \mathrm{~b}$ a menos respondida, totalizando 16 respostas em branco.

$\mathrm{Na}$ terceira parte do questionário, a qual teve como finalidade a análise do processo de ensino e aprendizagem de eletroquímica, obteve-se como resultado que grande parte dos alunos (12) classificaram o nível de dificuldade em aprender eletroquímica como 7 e 8 , ou seja, o conteúdo de oxirredução tende a ser mais difícil de se aprender. Apenas seis acadêmicos classificaram o nível de dificuldade como 5, categorizando o nível de dificuldade como intermediário. Em contrapartida, quanto à dificuldade em ensinar eletroquímica, 19 acadêmicos classificaram entre os valores de 5 a 8 , logo, os licenciandos afirmam que o nível de dificuldade em ensinar o conteúdo de oxirredução tende a ser de intermediário a difícil.

Quando questionados sobre quais conceitos de química os mesmos consideravam importantes, como conhecimento prévio para aprender sobre oxirredução, observa-se que a maioria considera que o estudo de reações químicas, da tabela periódica, dos elementos químicos e suas propriedades servem como pré-requisito para uma aprendizagem mais efetiva acerca de oxirredução. Além disso, os acadêmicos afirmam que é importante conhecer sobre os conceitos de eletroquímica para compreender como acontecem os fenômenos do seu cotidiano, como a condução de energia, a corrente elétrica e reações químicas.

Os licenciandos afirmam que o maior receio em lecionar esse conteúdo é o de não conseguir fazer com que os alunos consigam visualizar e compreender como a oxirredução ocorre, bem como não saberem diferenciar conceitos como ânodo e cátodo, nem saberem identificar quem são as espécies que reduzem e que oxidam, entre outros conceitos da eletroquímica que possam confundir os alunos. Há também o receio de não conseguirem adequar as suas aulas para que todos os alunos aprendam, ou de ter dúvidas em relação ao conteúdo.

Nessa parte do questionário, os estudantes puderam relatar quais foram suas principais dificuldades quando aprenderam

A obtenção de vários materiais utilizados pelo homem é realizada através do processo da eletrólise. O equipamento abaixo foi utilizado para efetuarmos a eletrólise de uma solução aquosa de cloreto de cobre II $\left(\mathrm{CuCl}_{2}\right)$ com eletrodos de carbono.

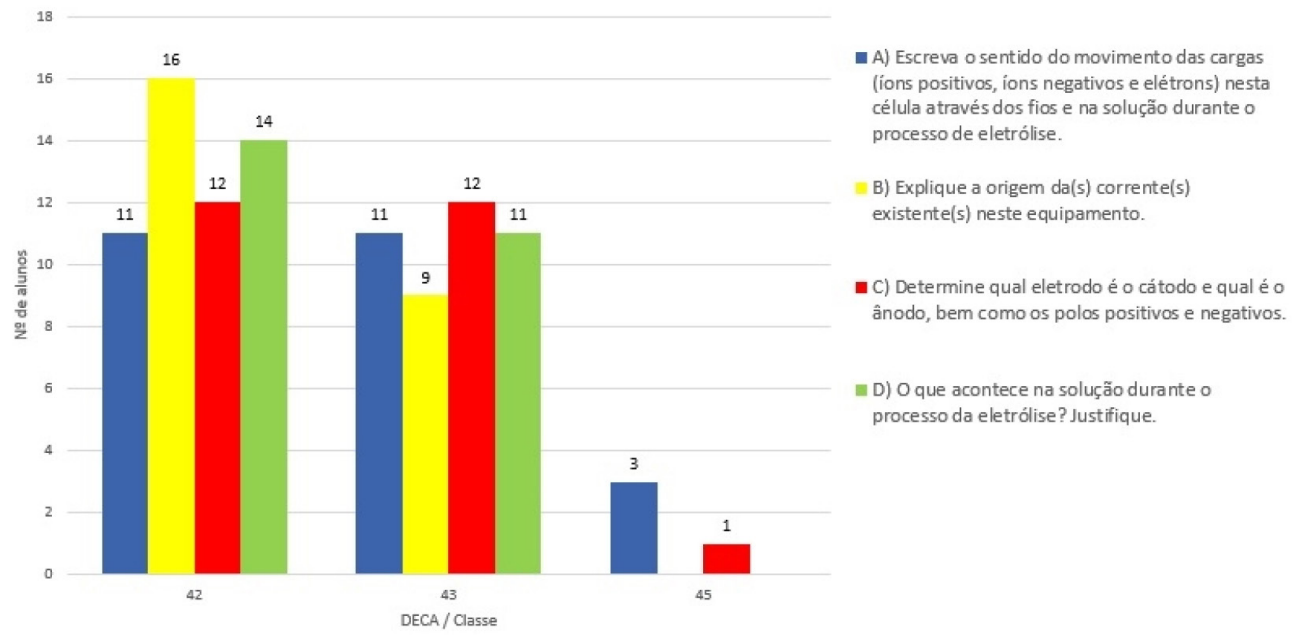

Figura 6. Categorias identificadas nas respostas à quarta questão 
sobre eletroquímica durante o ensino básico. As respostas obtidas apresentam que os mesmos tiveram dificuldades em saber diferenciar quem é o ânodo de quem é o cátodo, quais espécies oxidam ou reduzem, o fluxo dos elétrons, bem como a dificuldade em interpretar figuras, representações e esquemas. Alguns estudantes afirmam que o conteúdo foi abordado de forma muito superficial, ou seja, não houve de fato uma aprendizagem significativa. Apenas dois alunos relataram não ter tido dificuldades em aprender eletroquímica. Um dos licenciandos que participou do questionário relata: "Acho importante trabalhar o assunto, pois tentando fazer as questões acima (do questionário) percebi que não lembro nada sobre o assunto. Pode ter sido devido às aulas serem o mais rápido possível devido à pressa em aprender para passar no vestibular".

De um modo geral, os dados obtidos no presente estudo revelaram que a maioria dos licenciandos investigados possuem dificuldades de compreensão com o assunto eletroquímica, fato confirmado pelo alto indíce de respostas incorretas, confusões conceituais ou até mesmo respostas em branco para a segunda parte do questionário. Os resultados parecem sugerir que os estudantes se recordam ainda menos dos conteúdos relacionados à eletrólise e às células eletrolíticas de uma forma geral, pois a quantidade de alunos que não responderam à questão que envolvia esses assuntos foi maior do que na questão que abordava especificamente sobre as pilhas. Tal situação pode ser decorrente de que muitos professores deixam de abordar esses conteúdos quando lecionam a eletroquímica, enfatizando apenas o funcionamento das pilhas.

Embora a maioria dos estudantes tivesse finalizado a educação básica pouco tempo antes de ingressar no ensino superior (e responder ao questionário proposto nesse estudo), parece que o ensino de eletroquímica se deu de forma ineficaz, fazendo com que os estudantes lembrassem muito pouco dos assuntos estudados no ensino médio.

$\mathrm{O}$ fato de muitas vezes o professor não estar bem preparado para ensinar o conteúdo aos alunos, juntamente com a questão de ser um conteúdo de difícil compreensão, compromete de forma direta a aprendizagem dos alunos. A carga horária das aulas de Química no Ensino Médio também é outro ponto que merece destaque, pois dificulta a ação do professor em organizar todos os conteúdos previstos no currículo com o pouco tempo de aula disponível, fazendo com que, em muitos casos, o conteúdo seja ensinado de forma superficial. Além disso, a falta de domínio conceitual por parte dos professores, bem como a falta de vivência dos mesmos quanto ao uso de estratégias didáticas diferenciadas que favoreçam a compreensão sobre a eletroquímica, parecem ser motivos que também intensificam o efeito deficitário na aprendizagem dos estudantes, que chegam ao ensino superior com praticamente nenhuma base conceitual dos processos eletroquímicos.

A terceira parte do questionário revelou também que a maioria dos licenciandos consideram que aprender e ensinar eletroquímica é algo difícil e que, em alguns casos, não se sentem preparados para lecionar tal conteúdo, por terem consciência das dificuldades e lacunas de aprendizagem que trazem consigo.

Perante esse cenário, é fundamental refletir e discutir sobre tais resultados, a fim de buscar caminhos de superação dessas dificuldades no ensino superior e implementar medidas de precaução para que os licenciandos não reverberem suas dificuldades e limitações quando se tornarem professores, potencializando ainda mais a problemática.

Consideramos que o professor universitário deve investigar constantemente o conhecimento prévio de seus graduandos (especialmente os ingressantes) para não ignorar as dificuldades e lacunas de aprendizagem advindas da educação básica. A prática docente desse professor precisa ser planejada e guiada levando em consideração o que os alunos sabem e onde se quer chegar.

Dessa forma, torna-se importante que o professor, principalmente nas disciplinas introdutórias - como as de Química Geral, explore o uso de estratégias didáticas mais eficazes como simuladores, atividades experimentais, discussões, diferentes modos de representações, entre outras inovações que vão além do uso do quadro e da aula meramente expositiva, para que os conceitos básicos sejam (re)aprendidos com solidez e permitam que o graduando construa pensamentos mais complexos e aprendizagens mais elaboradas nas disciplinas subsequentes, a partir dessa base conceitual bem trabalhada.

\section{CONCLUSÕES}

Os resultados obtidos nesse estudo mostraram que os estudantes possuem grandes lacunas de aprendizagem do conteúdo de eletroquímica, de modo que a maioria dos participantes demonstrou não possuir uma base sólida de conhecimento em eletroquímica, apresentando respostas erradas ou até mesmo deixando de responder as questões. Notou-se que poucos estudantes conseguiram desenvolver respostas mais elaboradas, revelando algumas dificuldades, equívocos e concepções alternativas. Considerando que são alunos da primeira fase de um curso de graduação, pode-se inferir que tal resultado seja reflexo dos elementos relacionados ao processo ensino-aprendizagem desses estudantes ainda durante a educação básica. Esse quadro coloca o desafio de como lidar com tais dificuldades dos estudantes na continuidade de seus estudos, em especial no ensino superior. Porém, é importante que sejam criadas, já durante os primeiros contatos com a química, estratégias inovadoras que permitam maior familiarização do estudante com a química.

\section{REFERÊNCIAS}

1. Caramel, N. J. C.; Pacca, J. L. A.; Caderno Brasileiro Ensino de Física 2011, 28, 7

2. Freire, M. S.; Júnior, C. N. S.; Silva, M. G. L.; Anais do VIII Encontro Nacional de Pesquisa em Educação em Ciências - ENPEC, Campinas, Brasil, 2011.

3. Taber, K. S.; Chem. Educ.: Res. Pract. Eur. 2001, 2, 123.

4. Niaz, M.; Chacón, E.; J. Sci. Educ. Technol. 2003, 12, 129.

5. Barreto, B. S. J.; Batista, C. H.; Cruz, M. C. P.; Quim. Nova Esc. 2017, $39,52$.

6. Sanjuan, M. E. C; dos Santos, C. V.; Maia, J. O.; da Silva, F. A.; Wartha, E. J.; Quim. Nova Esc. 2009, 31, 190.

7. Lin, H. S.; Yang, T. C.; Chiu, H. L.; Chou, C. Y.; Proc. Natl. Sci. Counc. 2002, 12, 100 .

8. Bueso, A.; Furió, C.; Mans, C.; Enseñanza de las Ciencias 1988, 6, 244.

9. Caamaño, A. In Enseñar Ciencias, Jiménez Alexandre, M. P., coord.; Graó: Barcelona, 2007

10. Garnett, P. J.; Treagust, D. F.; J. Res. Sci. Teach. 1992, 29, 121.

11. Posada, J. M.; Sci. Educ. 1997, 81, 445.

12. Sanger, M. J.; Greenbowe, T. J.; J. Res. Sci. Teach. 1997, 34, 377.

13. Sanger, M. J.; Greenbowe, T. J.; J. Chem. Educ. 1997, 74, 819.

14. Sanger, M. J.; Greenbowe, T. J.; J. Chem. Educ. 1999, 76, 853.

15. Lima, V. A.; Marcondes, M. E. R.; Enseñanza de las Ciencias 2005, extra, 1.

16. Bardin, L.; Análise de conteúdo, Ed. 70: Lisboa, 2004

17. de Goes, L. F.; Fernandez, C.; Agostinho, S. M. L.; Anais do XVIII Encontro Nacional de Ensino de Química - ENEQ, Florianópolis, Brasil, 2016.

18. Brasil, Secretaria de Educação Básica - Ministério da Educação, Orientações Curriculares para o Ensino Médio. Volume 2. Ciências da natureza, matemática e suas tecnologias, Brasília, Brasil, 2006.

19. Bezerra, L. M.; Química: Ser Protagonista, $3^{\text {a }}$ ed., Edições SM: São Paulo, 2016, vol. 2. 